\title{
Os Motivos de Sucesso, Afiliação e Poder: Perfis Motivacionais de Estudantes de Graduação e Pós-Graduação e sua Relação com Níveis Remuneratórios
}

\author{
Arménio Rego \\ Aida Isabel Tavares \\ Universidade de Aveiro \\ Miguel Pina e Cunha \\ Universidade Nova de Lisboa \\ Carlos Cabral Cardoso \\ Universidade do Minho
}

\begin{abstract}
Resumo
Esta pesquisa expõe evidência empírica relativa aos motivos de sucesso, afiliação e poder, prosseguindo 3 objetivos: 1) relacionar esses motivos com as remunerações; 2) testar se os mestrandos denotam perfil motivacional distinto do que caracteriza os estudantes de graduação; 3) aferir se esse perfil é similar ao extraído de estudos anteriores, realizados com amostras portuguesas, e nos quais prepondera a motivação afiliativa. Recrutou-se uma amostra de 594 estudantes, dos quais 314 freqüentavam mestrado (exercendo atividade profissional) e 280 bacharelado ou licenciatura. Os motivos foram medidos através de um instrumento desenvolvido e validado previamente. Os resultados sugerem o seguinte: a) a remuneração correlaciona-se positivamente com o motivo de poder; b) o poder explicativo dos motivos para a remuneração é bastante inferior ao facultado pelo número de anos pós-licenciatura, parecendo que reforçam ou mitigam o efeito dessa experiência; c) relativamente aos restantes estudantes, os mestrandos revelam mais elevadas orientações para o sucesso e o poder; d) o perfil da amostra diferencia-se do padrão extraído de outras populações portuguesas pelo fato de denotar mais elevada motivação para o sucesso, não sendo possível, porém concluir se tal reflete a especificidade da amostra ou alguma alteração na configuração motivacional portuguesa.

Palavras-chave:Sucesso; afiliação; poder; remunerações; desempenho académico; perfil motivacional.
\end{abstract}

The Motives of Achievement, Affiliation and Power:

Post-graduation Student's Motivational Profiles and it's Relation with Individual Income

\begin{abstract}
This research concerns the motives of achievement, affiliation and power. It aims: a) to show how the motives explain income of individuals; b) to test if the postgraduate students denote a motivational profile different from the one of the graduate students; $\mathrm{c}$ ) to test if these profiles are similar to those extracted by Rego in Portuguese samples, in which the affiliation motive predominates. The sample comprises 314 postgraduate students and 280 graduate students. The motives were measured through a questionnaire previously developed and validated. The main findings are the following: a) income correlate positively with the power motive; b) the predictive power of motives to the income is lower than the one provided by the length of time after graduation; c) postgraduate students score higher than graduate students on the power and achievement motives; d) the pro file of the sample is different from the one extracted from previous Portuguese samples, although it is not possible to know if this is due to the specificity of the sample or to some change in the Portuguese motivational profile.

Keywords: Motives; achievement; affiliation; power; individual income; academic achievement; motivational profile.
\end{abstract}

Desde os trabalhos pioneiros de Murray (1938), é notória e exuberante a prolixidade de estudos que se debruçam sobre os motivos. Tal deve-se, em grande medida, ao reconhecimento de que eles ocupam um lugar importante no elenco dos diversos elementos psicológicos que compõem a personalidade dos indivíduos (Winter, 1998). Podem ser definidos como as predisposições específicas interiorizadas pelas pessoas através do processo de socialização, as quais se organizam sob forma hierárquica (i.e., em termos de perfis) e imprimem uma determinada direção ao comportamento (Reto, Cruz \& Lopes, 1989/1990). Os motivos predominantes nos inúmeros trabalhos de McClelland e seus colaboradores são os de sucesso, afiliação e poder, podendo estes ser assim caracterizados (Koestner \& McClelland, 1992; McClelland, 1987; McClelland \& Koestner, 1992; Winter, 1998):

a) $\mathrm{O}$ motivo de sucesso representa um interesse recorrente em fazer as coisas melhor, ultrapassando padrões de excelência. Os indivíduos bem cotados neste motivo têm um forte desejo de assumir responsabilidade pessoal por encontrar soluções para os problemas e preferem situações em que obtêm feedback acerca do seu desempenho. Manifestam preferência por tarefas de dificuldade intermédia, procuram alcançar objetivos elevados, mas realistas, reagem positivamente à competição, tomam iniciativas e são mais persistentes quando tentam levar a cabo uma tarefa ou realizá-la bem. Tendem a ser "irrequietos" e bem-sucedidos como empreendedores (Atkinson, 1966a, 1966b; Feather, 1966a, 1966b, 1966c; Littig, 1966; Litwin, 1966; McClelland, 1961/1976, 1962, 1987; McClelland, Atkinson, Clark \& Lowell, 1953; McClelland \& Koestner, 1992; Steers, 1983).

b) $\mathrm{O}$ motivo afiliativo representa um interesse recorrente em estabelecer, manter ou restaurar relações afetivas positivas (i.e., quentes e amistosas) com outras pessoas. Os indivíduos vincadamente motivados para a afiliação gostam de manter redes de relações interpessoais, tendem a ser mais cooperativos e a conformar-se mais com os desejos de outros, embora possam atuar irada e defensivamente sob condições de ameaça (Heyns, Veroff \& Atkinson, 1958; Koestner \& McClelland, 1992; McClelland, 1987). 
c) O motivo de poder representa um interesse recorrente em ter impacto sobre as pessoas, em afetar os seus comportamentos e emoções. Os mais motivados para o poder procuram controlar ou influenciar as outras pessoas, sentem-se atraídos por riscos elevados, procuram posições de liderança e prestígio e são mais competitivos do que os indivíduos com fraca orientação para este motivo (McCLelland, 1987; McClelland \& Burnham, 1976; McClelland \& Teague, 1975; Veroff, 1992a, 1992b; Winter, 1992a, 1992b).

Em torno deste trinômio é grande a profusão de estudos que têm vindo a ser desenvolvidos e publicados. Alguns abordam as suas origens e visam a saber, por exemplo, em que medida os padrões educacionais estão associados a determinados perfis motivacionais (McClelland, 1987; McClelland \& Pilon, 1983). Outras procuram estudar os seus efeitos, abrangendo um largo leque de tópicos, de que se ilustram: o desempenho académico dos estudantes (McClelland, 1972, 1987; Raynor, 1970; Rego, 1993, 1995, 1998a; Rego \& Carvalho, 2001, 2002), os estilos preferenciais de gestão do conflito (Ex.: Rego, 1995; Rego \& Jesuíno, 1999, 2002), a liderança organizacional (McClelland \& Burnham, 1976; McClelland \& Boyatzis, 1982; Miller \& Toulouse, 1986; Rego, 1995, 1998b, 1999; Winter, 1991), a liderança política (Hernann, 1980; Reto \& cols., 1989/1990; House, Spangler \& Woycke, 1991; Schmitt \& Winter, 1998; Winter, 1987, 1998), o desenvolvimento econômico das nações (McClelland, 1961/1976; Pereira, 1980), o empreendorismo e a orientação empreendedora (Johnson, 1990; McClelland, 1961/1976, 1965; Sagie \& Elizur, 1999) e o estado de saúde/doença dos indivíduos (Jemmott, 1987; McClelland, 1982, 1989; McClelland, Davidson \& Saron, 1985; Schultheiss, 1999).

\section{Objetivos da pesquisa}

Neste artigo, procurar-se-á facultar alguma contribuição adicional ao campo de estudos. Mais especificamente, procurarse-á responder a três indagações: 1) qual a relação entre os motivos dos indivíduos e os seus níveis remuneratórios?; 2) serão os perfis motivacionais dos alunos de mestrado distintos dos perfis de alunos de graduação?; 3) será que a marcada propensão afiliativa portuguesa é também encontrada entre estes estudantes? Antes da enunciação mais detalhada destes objetivos, justifica-se referir que a amostra é composta por estudantes do ensino superior, freqüentando bacharelados, licenciaturas e mestrados (exercendo estes, na sua maioria, atividade profissional remunerada). O estudo almeja lançar pistas de reflexão que permitam posteriormente aprofundar como se "comportam" os motivos noutras populações. Eis, então, os três objetivos da pesquisa.

Em primeiro lugar, testar-se-á como os motivos explicam os níveis remuneratórios dos indivíduos. A hipótese é a de que os mais motivados para o sucesso e para o poder auferem remunerações mais elevadas, ocorrendo o oposto com os mais afiliativos. Eis os fundamentos argumentativos:

a) Uma das características dos indivíduos mais motivados para o sucesso é o desejo de ultrapassar padrões de excelência. É, pois, presumível que denotem melhores desempenhos profissionais, assim progredindo para patamares de carreira mais elevados e obtendo concomitantes acréscimos salariais. Tendem, igualmente, a tomar iniciativa e são mais persistentes na realização das tarefas, posturas progressivamente valorizadas nas organizações hodiernas e, presumivelmente, associadas a melhores notações nas avaliações de desempenho. Procuram também feedback atinente ao sucesso da sua atividade. Sendo o dinheiro um sinal/ indicador por excelência desse sucesso, é plausível que o procurem mais intensamente do que os menos propensos para este motivo. Finalmente, dado que tendem a possuir mais elevadas classificações no curso (Rego, 1993, 1995, 1998a; Rego \& Carvalho, 2001, 2002), é provável que obtenham melhores empregos e maiores salários.

b) Os mais motivados para a afiliação valorizam as relações interpessoais, sendo natural que prezem as suas relações familiares e extra-profissionais em maior grau do que os menos afiliativos. É, portanto, provável que denotem menor grau de empenho na carreira e na vida profissional, fato que, porventura, traduziráse-á em mais fracos níveis salariais. Mesmo no seio dos ambientes de trabalho, tendem a atribuir mais importância às pessoas do que às tarefas, razão pela qual é presumível que apresentem desempenhos de nível inferior. Acresce que o esforço para conquistar amizades e restaurar relações, assim como o desejo de aprovação social, tenderão a ser, em certa medida, impeditivos do acesso a cargos de chefia, o que os afasta de uma possibilidade adicional de auferir rendimentos mais elevados. Finalmente, dado que os alunos mais afiliativos tendem a possuir mais fracas classificações no curso (Ex.: Rego, 1993, 1995, 1998a; Rego \& Carvalho, 2001, 2002), é provável que fiquem desprovidos de um dos elementos potencialmente indutores de melhores empregos e correspondentes salários, pelo menos no momento de ingresso no mercado de trabalho.

c) Os mais motivados para o poder tendem a procurar posições de prestígio e de reputação, parecendo razoável presumir que tais posições estejam associadas a superiores níveis remuneratórios. Também tendem a procurar funções de liderança, sendo plausível que as chefias usufruam de níveis salariais superiores aos dos seus subordinados. Ademais, é plausível que a necessidade de provocar impacto os conduza a procurar atividades e funções melhor remuneradas do que as exercidas por outras pessoas. Por outro lado, essa necessidade de provocar impacto e de exibir objetos de prestígio pode conduzi-los a uma busca mais intensa de poder aquisitivo. Finalmente, motivados para influenciar, e até dominar, é natural que não pretendam colocar-se em posições de dependência, o que tenderia a suceder se fossem postos numa posição social parca em recursos financeiros.

Em suma, é presumível que os mais motivados para o sucesso e o poder aufiram rendimentos superiores, o oposto ocorrendo com os mais motivados para a afiliação. O segundo aspecto sobre o qual se debruça este artigo diz respeito motivacional de estudantes de mestrado. Várias aduções podem ser traçadas:

a) Sendo este grau de ensino uma via de acesso potencial a cargos de maiores responsabilidades e remuneração, um elemento de 
prestígio e reputação social, bem como uma via potencialmente conducente à melhoria do desempenho profissional, é presumível que seja procurado por alunos com motivações para o poder e o sucesso mais elevadas do que, em geral, as dos estudantes freqüentadores de bacharelado e/ou licenciatura.

b) A frequência de um mestrado implica, normalmente, esforços de conciliação com a vida profissional e pessoal. Ademais, os custos financeiros de freqüência tendem a ser suportados pelos próprios - o que, em Portugal, tende a não ocorrer noutros níveis de ensino. Em ambas as condições, parece razoável supor que o ingresso neste nível de ensino seja uma opção mais plausível nos indivíduos profissionalmente "ambiciosos" - característica que os mais motivados para o sucesso e o poder presumivelmente possuem.

c) Embora admita exceções, a lei portuguesa condiciona o acesso aos mestrados a uma dada nota mínima de licenciatura e impele que a seleção seja realizada de acordo com esse critério de mérito. As exceções também apontam para o mérito, embora em domínios que não a nota média alcançada na licenciatura. Ao revelarem notas superiores, os mais motivados para o sucesso revelam também um provável mérito superior noutras atividades profissionais, sendo por isso maior a probabilidade de ingresso em pós-graduações.

d) Por seu turno, é plausível que os mais afiliativos, tendencialmente mais direcionados para as relações interpessoais e familiares, sejam mais renitentes em enveredar pela freqüência de uma graduação que, por tender a ser cumulativa com o exercício de atividade profissional e por ocupar o tempo destinado ao usufruto e manutenção das relações interpessoais, ameace essas mesmas relações e ponha em causa a estabilidade inter-relacional, cooperativa e familiar. Acresce ainda o fato de, tendencialmente, estes indivíduos não apresentarem bons desempenhos acadêmicos e serem, por isso, rejeitados nos processos de candidatura aos mestrados.

Em síntese, é presumível que, relativamente aos estudantes de bacharelado e de licenciatura, os alunos de Mestrado apresentem um perfil motivacional menos vincado em afiliação e mais vigoroso em sucesso e poder.

$\mathrm{O}$ terceiro aspecto visado pelo presente artigo remete para estudos que sugerem que a população portuguesa denota um perfil motivacional predominante em orientação afiliativa e fraco em motivação para o poder (Marques, 2001; Rego, 1993, 1995, 1998a, 2000). O motivo de sucesso parece ocupar uma posição intermédia, embora pareça ter vindo a tornar-se mais relevante ao longo dos últimos anos (Rego, 2000; Rego \& Carvalho, 2001, 2002). Importa enfatizar que este padrão tem sido colhido em amostras de estudantes freqüentando um diversificado leque de cursos, de gestores e de membros sem cargos de chefia de diversas organizações (Rego, 1998b, 2000). Ademais, ele justapõese ao perfil extraído por McClelland (1961/1976, 1987), com o recurso à análise de conteúdo de material semântico: 0,13 (sucesso), 0,72 (afiliação) e -1,17 (poder).

Um elemento adicional, atinente ao estudo das culturas nacionais, reitera este pendor afiliativo. $\mathrm{Na}$ classificação de Hofstede (1980, 1991), Portugal assoma como um "cultura feminina", isto é, promotora da qualidade do relacionamento interpessoal, contrariamente ao que tende a suceder numa cultura masculina, em que prevalece a orientação para os resultados, o sucesso e a competição. Este pendor feminino induziu Sakellarides a intitular uma entrevista a Hofstede do seguinte modo: "latinos são femininos, não machos". O título tenta fazer jus à resposta que Hofstede (1997) facultou à jornalista quando indagado sobre o que lhe parecia distinto na cultura portuguesa:

Portugal é um país tipicamente latino, pertencendo, por isso, ao grupo mais feminino. No entanto, reconheci imediatamente que os portugueses diferem dos outros países latinos e, ao contrário dos espanhóis, não matam os seus touros. Os portugueses tendem a ser mais simpáticos para as pessoas e são bons negociadores, tentando sempre encontrar uma via pacífica. Por isso, resolvem muitos problemas negociando e não guerreando. (p. 40)

Notavelmente, Gannon, num livro ainda mais recente (2001), destinado a comparar as culturas de 23 nações, reiterou a referência feita por Hofstede e conotou Portugal com uma metáfora: 'Tourada portuguesa", contrastando-a também com a tourada espanhola.

O que importa aprofundar é se este pendor afiliativo é reiterado em amostras peculiares, não representativas da população portuguesa - como é o caso de mestrandos. Este é, por conseguinte, o terceiro objetivo da presente pesquisa.

\section{A mensuração dos motivos}

Uma das mais exuberantes controvérsias em torno dos motivos é a atinente aos métodos de mensuração. A preferência de McClelland sempre incidiu sobre uma técnica projectiva designada, por vezes, de Picture-Story Exercise (Koestner \& McClelland, 1992). Trata-se de um "teste de apercepção temática" (TAT), desenvolvido originalmente por Murray (1938), que consiste numa série de figuras mostrando pessoas em situações ambíguas, perante as quais se solicita às pessoas que inventem uma história. Presume-se que estes relatos inventivos revelam os sonhos, as fantasias e as aspirações dos indivíduos, tendo sido desenvolvidos sistemas de codificação que permitem analisar o conteúdo de cada história e pontuá-la nos três motivos (Heyns \& cols., 1958; McClelland \& cols., 1953; Veroff, 1992a; Winter, 1992a).

Existe, todavia, alguma polêmica acerca das vantagens desse método face aos questionários (Atkinson, 1982; Atkinson \& Birch, 1986; Fleming, 1982; McClelland, 1987; McClelland, Koestner \& Weinberger, 1989; Spangler, 1992; Smith, 1992; Schmalt, 1999; Sokolowski, Schmalt, Langens \& Puca, 2000; Weinberger \& McClelland, 1990; Weiner, 1989; Winter \& Stewart, 1977):

a) Os críticos do TAT alegam que ele é um método pouco fidedigno

(seja do ponto de vista do teste-reteste, seja da consistência interna) e frouxamente preditivo dos comportamentos humanos. Em contrapartida, advogam que os questionários demonstram adequada fidedignidade e maior valor preditivo.

b) Os paladinos do TAT concordam em que ele é um método muito sensível a influências situacionais. Mas alegam ser possível obter bons índices de fidedignidade se o teste for administrado corretamente. Quanto aos questionários, aduzem, ainda, que a sua fidedignidade tem sido exagerada. No entanto, advogam que o poder preditivo do TAT é superior no que concerne aos comportamentos de longo prazo. Finalmente, esclarecem que, 
sendo inconscientes, os motivos não "devem" ser medidos por meio de escalas em que se convidam os indivíduos a autodescreverem-se.

c) Alguns autores argumentam que os dois métodos são equivalentes. A plausibilidade desta tese é, todavia, seriamente posta em xeque pelo fato de os dados disponíveis apontarem para a pequena ou nula correlação entre os motivos medidos pelas duas vias.

Uma posição distinta é que advoga que os motivos medidos pelas duas vias são conceitualmente diferentes. Mais especificamente, McClelland e colaboradores (Koestner \& McClelland, 1992; Mclelland, 1987; McClelland \& cols., 1989; McClelland \& Koestner, 1992; Weinberger \& McClelland, 1990) procedem à distinção entre os motivos implícitos (medidos pelo TAT) e os motivos explícitos ou auto-atribuídos (medidos pelos questionários). Os primeiros, sendo inconscientes, refletem-se nas fantasias descritas pelos indivíduos quando são colocados perante as figuras ambíguas do TAT. Os segundos, sendo conscientes, podem ser descritos pelos indivíduos quando questionados diretamente sobre as duas disposições motivacionais, objetivos e preferências em situações específicas. Aduzem os investigadores que os dois tipos de motivos denotam validade de constructo em áreas diferentes (Schmalt, 1999; Sokolowski \& cols., 2000):

a) Os motivos implícitos explicam bem o que as pessoas realmente fazem, como despendem o seu tempo e o seu comportamento operante a longo prazo (como a progressão na carreira profissional);

b) Os explícitos são bons preditores das atitudes, valores e objetivos conscientes, especialmente quando é requerido esforço.

Esta dicotomia foi alvo de escrutínio por parte de Schmalt (1976), que desenvolveu aquilo que se pode chamar a "terceira via": a técnica da grelha, a qual combina as características do TAT e dos questionários. Tal como no TAT, os indivíduos são colocados perante uma série de figuras ambíguas. Mas, em vez de serem convidados a descreverem (inventarem) histórias, são induzidos a responder a diversas questões para cada uma das figuras. Estas questões incorporam tendências motivacionais relacionadas com as emoções, as cognições, a antecipação de objetivos e as ações instrumentais. Por exemplo, perante uma determinada figura, é solicitado aos inquiridos que refiram em que grau o indivíduo nela representado se sente bem, está ou não satisfeito com o que está fazendo, apercebe-se ou não capaz de realizar a tarefa. Os trabalhos empíricos que têm sido desenvolvidos (Schmalt, 1999; Schmalt \& Sokolowski, 2000; Sokolowski \& cols., 2000) sugerem que o instrumento denota boas propriedades psicométricas.

No estudo cujos resultados aqui se enunciam, recorreu-se a um questionário. A grande vantagem deste método reside no fato de ser mais prático, mais facilmente aplicável, mais rápido e mais barato. Conseqüentemente, diversas tentativas têm sido feitas com o objetivo de erigir um instrumento de medida com boas qualidades psicométricas (Meharabian, 1969; Spence \& Helmreich, 1983; Stahl \& Harrell, 1982; Steers \& Braunstein, 1976). Um dos exemplos mais recentes foi protagonizado por Rego e colaboradores (Rego, 1993, 1995, 1998a, 1998b, 2000; Rego \& Carvalho, 2001, 2002; Rego \&
Jesuíno, 2002), ao adotarem uma versão modificada e adaptada do questionário de medida das necessidades manifestas de Steers e Braunstein (1976). Projetando uma análise global sobre a investigação realizada, é possível aduzir que o questionário apresenta razoáveis propriedades psicométricas, em vários planos: a) consistência interna; b) relação com o TAT; c) poder preditivo dos estilos de gestão do conflito, dos impactos dos líderes sobre os seus subordinados e do desempenho acadêmico dos estudantes universitários. Por exemplo: a) Os índices de consistência interna são tendencialmente iguais ou superiores a 0,70 , sendo estes coeficientes mais satisfatórios nas últimas e mais refinadas versões do instrumento;

b) Em geral, o perfil traçado para amostras portuguesas coincide com o obtido por McClelland (1961/1976, 1987) a partir da análise de material semântico;

c) Esse padrão, embora não completamente coincidente, é semelhante ao obtido numa pesquisa em que Rego (1993) recorreu ao TAT. Nessa mesma investigação, ambas as medidas (TAT e questionário) denotaram relações idênticas entre os três motivos e o desempenho acadêmico de estudantes universitários.

Na sua forma atual (Rego \& Carvalho, 2001, 2002), e após ter sido submetido a um processo de depuração que lhe melhorou as qualidades psicométricas, o instrumento integra 18 itens (5 para o sucesso, 7 para a afiliação e 6 para o poder). A análise fatorial confirmatória (Byrne, 1998; Joreskog \& Sorbom, 1993) sugere que o esquema tri-factorial se ajusta satisfatoriamente aos dados (Ex.: goodness of fit index: 0,92). E os alphas de Cronbach ultrapassam o patamar mínimo de 0,70 sugerido por Nunnally (1978).

\section{Método}

Foi inquirida uma amostra constituída por 594 estudantes oriundos de 7 instituições de ensino superior portuguesas, dos quais 244 freqüentavam mestrado e 355 bacharelado ou licenciatura (ver caracterização mais detalhada no Anexo A); 61\% da amostra eram do sexo feminino. Todos foram convidados a responder ao questionário de medida dos motivos antes mencionado. Aos estudantes de bacharelado e de licenciatura foi ainda solicitado que facultassem dados sobre a idade, o gênero e a nota média obtida nas disciplinas em que já haviam obtido aprovação. Aos mestrandos foi solicitado que referissem a idade, o gênero, a nota final de curso de licenciatura, o tempo decorrido desde a conclusão da mesma e o rendimento líquido mensal auferido na atividade profissional atual.

Os dados relativos aos motivos foram submetidos a uma análise fatorial confirmatória (Byrne, 1998; Joreskog \& Sorbom, 1993), tendo sido testado o modo tri-fatorial sugerido em pesquisas anteriores (Rego \& Carvalho, 2001, 2002). Os resultados estão apresentados na Tabela 1 e sugerem que o modelo se ajusta satisfatoriamente aos dados. Os coeficientes de consistência interna relativos aos motivos de sucesso e de afiliação superam o nível mínimo sugerido por Nunnally (1978), o mesmo não ocorrendo no que concerne ao motivo de poder (embora o valor se situe em patamar próximo). Foram posteriormente realizados diversos testes estatísticos (correlações, regressões, análises de variância) tendo em vista responder aos objetivos da pesquisa. 
Tabela 1

Motivos: Análise Fatorial Confirmatória

Sucesso

-Gosto de aperfeiçoar constantemente as minhas competências pessoais.

-Esforço-me por melhorar os meus resultados anteriores.

0,63

-Gosto de saber se o meu trabalho foi ou não bem realizado, de modo a fazer melhor no futuro

0,71

- No trabalho, procuro fazer cada vez melhor.

0,68

0,77

- Tento fazer o meu trabalho de modo inovador.

0,46

Afiliação

$(0,75)$

-Gosto de ser solidário com as outras pessoas, mesmo que não sejam das minhas relações.

0,52

-Sinto satisfação quando vejo que uma pessoa que me pediu ajuda fica feliz com o meu apoio.

-Se tivesse que despedir uma pessoa, procuraria sobretudo compreender os seus sentimentos

e apoiá-la no que me fosse possível.

- No trabalho, gosto de ser uma pessoa amável.

0,65

-Sinto-me satisfeito por trabalhar com pessoas que gostam de mim.

- No trabalho, presto muita atenção aos sentimentos dos outros.

- Fico preocupado quando sinto que, de alguma forma, contribui para o mal-estar das relações no trabalho. 0,52

Poder

'Tenho um desejo secreto de chamar a atenção das pessoas.

-Insisto numa determinada opinião apenas para "não dar o braço a torcer".

'Tenho discussões com os outros porque costumo insistir naquilo que penso que deve ser feito.

-Procuro relacionar-me com pessoas influentes.

-Se puder chamar pessoas para o trabalho da minha equipa, procuro as que me permitam exercer mais influência. 0,55

-Quando participo de algum convívio, aproveito para influenciar os outros e obter o seu apoio para aquilo que quero fazer.

\begin{tabular}{lcc} 
& & 0,57 \\
\hline$\chi^{\prime \prime} / g l$ & Indices de ajustamento & 2,1 \\
Root mean square error of approximation & & 0,04 \\
Goodness of fit index & & 0,95 \\
Adjusted goodness of fit index & 0,94 \\
Comparative fit index & 0,93 \\
Incremental fit index & 0,93 \\
Relative fit index & 0,85 \\
\hline
\end{tabular}

Nota. Entre parênteses: alphas de Cronbach

Tabela 2

Médias, Desvios-padrão e Correlações

\begin{tabular}{lrrrrrrrr}
\hline & $m(d p)$ & 1 & 2 & 3 & 4 & 5 & 6 & 7 \\
\hline 1. Sucesso & $6,0(0,68)$ & - & & & & & & \\
2. Afiliação & $5,8(0,65)$ & $0,27 * * *$ & - & & & & & \\
3. Poder & $3,6(0,82)$ & 0,07 & $-0,08$ & - & & & \\
4. Média actual de curso (bach. e licenc.) & $12,03(1,12)$ & 0,12 & $-0,07$ & $-0,08$ & - & & \\
5. Média final de curso (mestrandos) & $14,02(1,22)$ & 0,00 & 0,11 & $-0,06$ & $\mathrm{Na}$ & - & & \\
6. Idade & $31,5(7,28)$ & $-0,03$ & $-0,13$ & $-0,03$ & 0,34 & $-0,24^{* *}$ & - \\
7. Tempo decorrido após a licenciatura (anos) & $6,8(5,59)$ & $-0,12$ & $-0,11$ & $-0,07$ & $\mathrm{Na}$ & 0,01 & $0,60 * * *$ & - \\
8. Remuneração (euros) & $1625(840)$ & 0,05 & $-0,13$ & 0,16 & na & 0,08 & $0,29^{* * *}$ & $0,47 * * *$
\end{tabular}

*Nota. $p<0,05 \quad{ }^{* *} p<0,01 \quad * * * p<0,001 \quad$ Na: não aplicável

\section{Resultados}

A Tabela 2 reporta as médias, os desvios-padrão e as correlações entre as variáveis. Os motivos afiliativo e de sucesso correlacionamse positivamente. A idade correlaciona-se negativamente com a média final de curso obtida pelos alunos que agora freqüentam o mestrado. Naturalmente, a idade e o período temporal decorrido após licenciatura correlacionam-se positivamente de modo bastante forte. No que concerne à remuneração, detecta-se que tende a incrementar com a idade, mas, especialmente, com o tempo decorrido após a conclusão da licenciatura.

Note-se que nenhum dos motivos se correlaciona significativamente com o desempenho acadêmico, nem com a remuneração. Todavia, no que diz respeito ao desempenho acadêmico, a evidência altera-se quando se calcula a correlação parcial (com o controle da variável curso). Aí, agregando todos os inquiridos, os coeficientes de correlação assumem magnitudes estatisticamente significativas $(p<0,05)$ : sucesso $(r=0,12)$, afiliação $(r=0,18)$ e poder $(r=0,12)$. De modo similar, quando a correlação entre os motivos e a 
remuneração é calculada com o controle do tempo decorrido póslicenciatura, o coeficiente relativo ao motivo do poder assume valor estatisticamente significativo $(r=0,20 ; p<0,05)$. Algo similar é detectado quando são controlados os efeitos da idade $(r=0,17$; $p<0,05)$. A evidência releva porque permite discernir entre o papel explicativo devido à "antiguidade" e o referente à motivação, fato aliás reiterado nas análises estatísticas posteriores.

A Tabela 3 representa os resultados dos coeficientes estimados das regressões para a remuneração. Num primeiro passo, foi apenas inserido o período temporal pós-curso, sendo depois acrescentados os três motivos. A evidência denota que o tempo decorrido após o curso explica $22 \%$ da variância do rendimento auferido, mas a motivação para o poder permite um incremento de $3 \%$. Quando este motivo é inserido na regressão em primeiro lugar, explica mais de $2 \%$ da variância da remuneração, sendo o tempo póscurso responsável por um incremento de $23 \%$.

As Figuras 1.1, 1.2 e 1.3 ajudam a compreender como as duas variáveis atuam, acrescentando, aliás, alguma evidência em matéria de motivação para o sucesso. A tendência é a de que a antiguidade explica invariavelmente a remuneração, quaisquer que sejam os níveis motivacionais dos indivíduos. Ademais, os indivíduos menos

Tabela 3

Regressões para o Rendimento Auferido

\begin{tabular}{lc}
\hline Tempo pós-curso & $0,48^{* * *}$ \\
Sucesso & 0,11 \\
Afiliação & $-0,10$ \\
Poder & $0,15^{*}$ \\
$\mathrm{~F}$ & $12,41^{* * *}$ \\
$\mathrm{R}^{2}$ ajustado & $24,9 \%$ \\
\hline $\mathrm{R}^{2}$ gerado pelo tempo pós-curso & $21,9 \%$ \\
Variação no $\mathrm{R}^{2}$ facultada pelos motivos (depois & $3 \%$ \\
do tempo pós-curso) & \\
$\mathrm{R}^{2}$ gerado pelos 3 motivos & $2,3 \%$ \\
Variação no $\mathrm{R}^{2}$ facultada pelo tempo pós-curso & $22,6 \%$ \\
(depois dos motivos) & \\
\hline
\end{tabular}

Nota. ${ }^{*} p<0,05 \quad{ }^{* *} p<0,01{ }^{* * *} p<0,001$

afiliativos auferem melhores rendimentos do que os restantes e o mesmo sucede como os mais motivados para o poder, qualquer que seja a "antiguidade". Mas a evidência relativa ao motivo de sucesso revela um padrão distinto: os que denotam orientação mais vincada obtêm remuneração significativamente superior aos restantes, mas apenas entre os que concluíram o curso há mais tempo. $\mathrm{O}$ dado sugere que esta orientação motivacional apenas surte efeitos remuneratórios à medida que o indivíduo vai progredindo na sua vida profissional. Frise-se, a título de curiosidade, que um padrão similar é observável a propósito da média de curso, cujo efeito parece apenas fazer sentir-se após alguns anos de experiência profissional.

A Tabela 4 sugere que os mestrandos, relativamente aos restantes estudantes, são mais motivados para o sucesso e o poder, não se detectando qualquer diferença significativa no que concerne ao motivo afiliativo. O perfil da amostra global e das sub-amostras coloca em último lugar o motivo de poder,
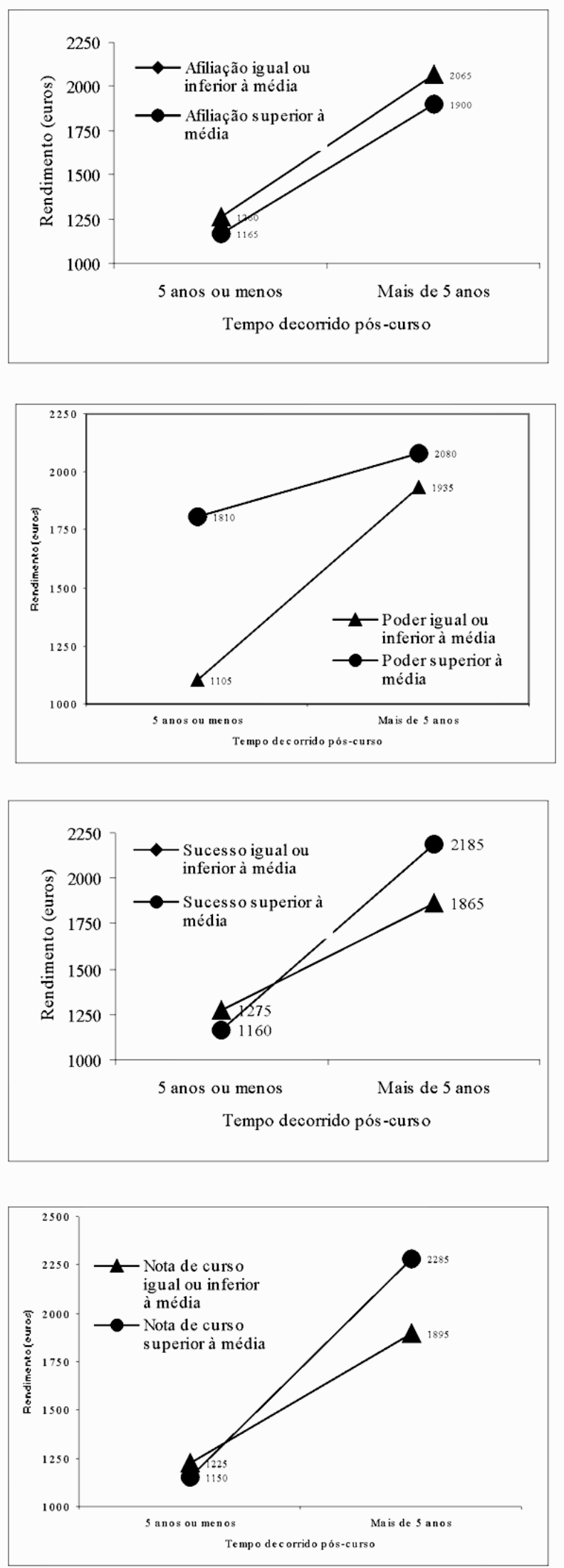

Figuras 1.1, 1.2 1.3, 1.4. Como os motivos, a média final de curso e o tempo decorrido após o mesmo explicam a remuneração. 
Tabela 4

Perfis Motivacionais dos Indivíduos: Mestrandos vs. Restantes

\begin{tabular}{lccc}
\hline & Total & Mestrandos & $\begin{array}{c}\text { Restantes } \\
\text { (bach }+ \text { licenc. }) \\
(n=314)\end{array}$ \\
\hline Sucesso & 6,0 & 6,3 & $5,8 * * *$ \\
Afiliação & 5,8 & 5,8 & 5,8 \\
Poder & 3,6 & 3,7 & $3,5^{* * *}$ \\
\hline
\end{tabular}

Nota. ${ }^{* * *} p<0,001$ (teste $\mathrm{T}$ )

situando as duas outras orientações num plano muito similar, embora ligeiramente favorável ao sucesso.

Um dado adicional que auxilia na compreensão desta matéria está registrado na Tabela 5. Aí se expõe o modo como os indivíduos mais e menos orientados para cada motivo se distribuem pelas duas categorias de estudantes. A evidência sugere claramente que os mais motivados para o sucesso e para o poder estão sobre-representados no grupo de mestrandos, estando os menos orientados para esses motivos sobrerepresentados no grupo dos restantes alunos. Não se vislumbra qualquer tendência de desigualdade de distribuições no que concerne ao motivo afiliativo.

\section{Discussão}

A primeira indicação facultada pelos dados é a de que os mais elevados rendimentos auferidos pelos indivíduos podem estar associados a uma mais elevada motivação para o poder (e, mais tenuemente, para o sucesso), assim como a uma mais baixa propensão afiliativa. Importa notar que a evidência é clara ao sugerir que o tempo decorrido após a conclusão do curso denota poder explicativo bastante superior ao propiciado pelos três motivos, mas estes não são irrelevantes. Em termos gerais, pode considerar-se que os indivíduos "asseguram" incrementos salariais em função da sua experiência profissional e/ou antigüidade, mas as suas motivações reforçam ou atenuam esse crescimento. Estes dados não são surpreendentes se atendermos à caracterização de cada motivo:

a) Compreende-se que os mais motivados para o sucesso aufiram melhores rendimentos do que os restantes: a sua maior iniciativa, a busca de excelência, a procura de modos inovadores de resolver os problemas e a maior persistência na realização das tarefas tenderão a induzir-lhes níveis superiores de desempenho profissional, maior ambição e, conseqüentemente, melhores remunerações;

b) Também é compreensível que os mais motivados para o poder aufiram melhores rendimentos. Em primeiro lugar, porque é provável que exerçam funções de chefia em maior grau do que os restantes indivíduos, sendo estas atividades melhor remuneradas. Em segundo lugar, porque as suas necessidades de prestígio, de reputação e de controle presumivelmente os impelem na senda de atividades e de desempenhos profissionais que thes facultem remunerações superiores. Em terceiro lugar, porque a propensão para exercerem influência os pode induzir na gestão de impressões e na adoção de outras táticas de influência que lhes permitam ser alvo de melhores classificações nas avaliações de desempenho;

c) Finalmente, compreende-se que os mais afiliativos tendam a auferir mais fracos rendimentos. Esse é, porventura, o corolário de propenderem mais para as relações interpessoais harmoniosas, de serem menos atreitos a atividades de chefia e de concederem maior prioridade à vida familiar e social (em detrimento da profissional).

Embora expectáveis, estes elementos empíricos acrescentam alguma valia a um domínio ainda fortemente inexplorado. A sua consideração recomenda, todavia, que se tomem algumas precauções e que estudos posteriores sejam executados. Na verdade, a amostra é constituída por indivíduos com atributos

Tabela 5

Como os Mais e os Menos Orientados para cada Motivo se Distribuem pelas duas Categorias de Estudantes

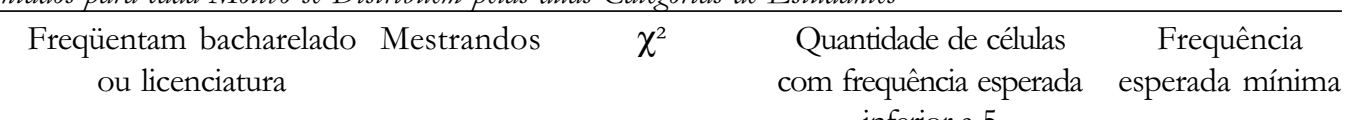

\begin{tabular}{|c|c|c|c|c|c|c|}
\hline \multirow{3}{*}{ Sucesso } & & & & \multirow{3}{*}{$58,95^{* * *}$} & \multirow{3}{*}{0} & \multirow{3}{*}{133} \\
\hline & Abaixo da média & $\begin{array}{c}197+ \\
(150)\end{array}$ & $\begin{array}{c}87- \\
(133)\end{array}$ & & & \\
\hline & Acima da média & $\begin{array}{l}117- \\
(164)\end{array}$ & $\begin{array}{c}192+ \\
(145)\end{array}$ & & & \\
\hline \multirow[t]{2}{*}{ Afiliação } & Abaixo da média & $\begin{array}{c}115 \\
(118)\end{array}$ & $\begin{array}{c}107 \\
(104)\end{array}$ & \multirow[t]{2}{*}{0,25} & \multirow[t]{2}{*}{0} & \multirow[t]{2}{*}{104} \\
\hline & Acima da média & $\begin{array}{c}199 \\
(196)\end{array}$ & $\begin{array}{c}170 \\
(172)\end{array}$ & & & \\
\hline \multirow[t]{2}{*}{ Poder } & Abaixo da média & $\begin{array}{c}166+ \\
(146)\end{array}$ & $\begin{array}{l}108- \\
(128)\end{array}$ & \multirow[t]{2}{*}{$11,40^{* * *}$} & \multirow[t]{2}{*}{0} & \multirow[t]{2}{*}{128} \\
\hline & Acima da média & $\begin{array}{l}148- \\
(168)\end{array}$ & $\begin{array}{c}169+ \\
(148)\end{array}$ & & & \\
\hline
\end{tabular}

Nota. Os valores da primeira linha reportam a freqüência encontrada; os da segunda dizem respeito à frequência esperada.

Os sinais $+\mathrm{e}-$ significam que a frequência encontrada é, respectivamente, superior ou inferior à esperada.

Psicologia: Reflexão e Crítica, 2005, 18(2), pp.225-236 
muito peculiares, já licenciados e freqüentadores de um mestrado. Estudos posteriores deverão colher amostras de maior dimensão e contendo indivíduos com mais amplos leques de habilitações acadêmicas e de antigüidades. Eis algumas indagações pertinentes que tais pesquisas poderão percorrer: a) Será a experiência igualmente relevante para indivíduos de diferentes graus acadêmicos?; b) Serão as motivações mais importantes para as pessoas desprovidas de grau acadêmico superior? Ou seja: poderão as suas orientações motivacionais reforçar ou mitigar a ausência de curso superior?

O segundo domínio de interesse empírico sobre o qual se debruçou esta pesquisa é referente aos perfis motivacionais dos mestrandos versus os dos estudantes de graduação. Embora seja tênue a tendência dos primeiros para um menor pendor afiliativo, são claras as suas superiores orientações para o sucesso e o poder. A evidência é retratada tanto pelas comparações de médias (Tabela 4), quanto pela distribuição dos mais e menos orientados para cada motivo por categorias de estudantes (Tabela 5). Também neste particular domínio, os dados eram expectáveis:

a) Sendo mais ambiciosos e mais vocacionados para a excelência e tendo espírito de iniciativa mais vincado - é presumível que os mais motivados para o sucesso busquem mais intensamente $\mathrm{O}$ acesso a um mestrado. A esse fato acresce o de estarem mais habilitados para tal, já que tendem a obter melhores classificações durante o curso de licenciatura, como têm sugerido diversas investigações (Ex.: Rego, 1993, 1995, 1998a; Rego \& Carvalho, 2001, 2002). Deve, aliás, considerar-se a séria verossimilhança de os mais motivados para o sucesso envidarem mais esforços durante a licenciatura para obterem classificações superiores, precisamente com o objetivo de ingressarem posteriormente num mestrado;

b) Também é plausível que por desejarem funções de maior prestígio e reputação, assim como por almejarem exercer atividades de autoridade, os mais motivados para o poder tentem mais afincadamente aceder a um mestrado.

Em qualquer caso, aduz-se aqui a necessidade de estudos posteriores acolherem um leque mais amplo de cursos, tanto de graduação como de pós-graduação. Será porventura interessante testar, por exemplo, se os indivíduos da mesma área profissional (Ex.: direito, línguas, economia) que freqüentam um mestrado denotam padrões motivacionais mais vincados em sucesso e poder do que os seus congêneres freqüentando uma licenciatura. Essa pode ser, porventura, uma via mais profícua do que comparar genericamente os estudantes de graduação, com os de pós-graduação. Como nota complementar a esta reflexão, deve, porém, referir-se um dado empírico facultado pelos nossos dados. Ele resultou da extração de um grupo peculiar de estudantes (da área da gestão) em cada nível:

a) nos alunos de licenciatura, foram agregados os estudantes de Engenharia e Gestão Industrial com os de Gestão e Planeamento em Turismo; b) nos alunos de mestrado, congregaram-se os de MBA, Gestão das Operações, Gestão Pública, Gestão da Informação e Gestão de Recursos Humanos. Os dados corroboram, pois, a tendência antes delineada: os mestrandos são significativamente mais motivados para o sucesso $(6,2 v$ s. 5,9; $p<0,001)$ e para o poder $(3,7 v$ s.
$3,4 ; p<0,01)$. Em qualquer caso, parece necessário que estudos posteriores testem essa diferença, de um modo mais sistemático, no seio das mesmas áreas científicas e técnicas. A legitimidade desta precaução é, aliás reforçada pela exigüidade das diferenças, que, embora estatisticamente significativas, não permitem extrair conclusões peremptórias.

E é nesta matéria que outro caminho de pesquisa se justifica. $\mathrm{Na}$ verdade, a comparação entre estudantes de mestrado e de graduação, executada deste modo, padece da dificuldade de, entre os segundos, haver indivíduos que posteriormente ingressam em mestrado. $\mathrm{O}$ cotejo não se faz, portanto, entre indivíduos que ingressam num mestrado e os que não ingressam. Faz-se, antes, entre a) uma população que ingressou; b) e outra população englobando indivíduos que ingressarão e outros que ficarão afastados. Portanto, é possível que a metodologia usada neste estudo seja responsável pela pequenez das diferenças citadas. Parece recomendável, por conseguinte, recorrer a outras soluções metodológicas. Por exemplo: a) num dado momento, medir os perfis motivacionais de estudantes que freqüentam as licenciaturas; b) num momento posterior, testar se há diferenças motivacionais entre os que ingressaram num Mestrado e os restantes. A longitudinalidade comporta dificuldades consideráveis, mas parece incontornável para robustecer a resposta à hipótese apresentada neste artigo.

Cabe agora comentar a evidência relativa à terceira indagação da pesquisa: será que a hierarquia motivacional (afiliação, sucesso e poder, por ordem decrescente) que tem emergido em diversos estudos com populações portuguesas é replicável em amostras específicas, como a que foi aqui colhida? A resposta é parcialmente positiva.

Primeiro: os dados corroboram a fraca orientação para o poder. Fazem, por conseguinte, jus à diversa evidência empírica obtida (Ex.: Marques, 2001; McClelland, 1961/1976, 1987; Rego, 1993, 1995, 1998a, 1998b, 2000; Rego \& Carvalho, 2001, 2002) com diferentes métodos de medida dos motivos (questionários, TAT, análise de material semântico recolhido em histórias contadas a crianças). A robustez desta tendência é claramente refletida no fato de vir sendo reiterada em amostras de constituições muito díspares: estudantes de uma grande diversidade de cursos, gestores, membros de diferentes organizações sem funções de chefia. Embora tal não tenha sido autonomizado no panorama empírico exposto, cabe aqui sublinharse que, na presente amostra, o terceiro lugar do motivo é invariavelmente detectado nas várias sub-amostras (ver Anexo A).

Segundo: a posição relativa dos motivos de sucesso e afiliativo assume, porém, um pendor distinto. $\mathrm{Na}$ verdade, a predominância afiliativa demonstrada em diversos estudos dá aqui lugar à equiparação entre ambos os motivos, aliás com ligeira preponderância do sucesso. Note-se que não ocorre uma diminuição da orientação afiliativa, mas antes se assiste ao incremento do motivo de sucesso. Esta particularidade (que representa alguma descontinuidade face a estudos anteriores) dá aso a argumentação e hipóteses explicativas várias:

a) Pode suceder que, tal como Rego (2000) aduziu, esteja em curso um incremento da motivação para o sucesso na população portuguesa. Eis um elenco de fatores potencialmente contributivos desse incremento: alterações políticas, mudanças no sistema de ensino, modificações nos padrões educacionais colhidos no seio 
da família, ruptura com padrões sociais/culturais prévios à Revolução de 1974 e inserção da vida portuguesa no contexto de correntes culturais e sociais tipicamente europeias/ocidentais. Alternativamente, é possível que a ascensão da cotação no motivo de sucesso seja mais o fruto das alterações psicométricas introduzidas no instrumento de medida dos motivos (a partir de Rego, 2000) do que o resultado de reais alterações no padrão motivacional português;

b) Esta hipótese comporta, todavia, uma possibilidade inversa: a de o instrumento, após os aprimoramentos introduzidos por Rego (2000), medir mais apropriadamente a configuração motivacional portuguesa. Nesse caso, a equiparação entre os motivos de sucesso e afiliativo refletiria mais fielmente a realidade. Esta possibilidade é, aliás, condizente com os resultados facultados por uma pesquisa realizada por Rego $(1993,1995)$ com o recurso ao TAT;

c) Resta uma alternativa explicativa: a de a equiparação entre os dois motivos representar a especificidade da amostra e não propriamente um traço cultural português. Em favor desta explicação, apresenta-se o fato de os estudantes de bacharelado apresentarem um perfil mais condizente com a prevalência afiliativa (6,0 no motivo de afiliação contra 5,6 na motivação para o sucesso). Assoma igualmente o fato de a motivação para o sucesso acompanhar o patamar de ensino dos estudantes: 5,6 para os alunos de bacharelado, 5,9 para os de licenciatura, 6,2 para os de Mestrado. Apresenta-se, também, o dado revelado por Rego (2000) segundo o qual os menos academicamente habilitados tendem a ser mais afiliativos. Por conseguinte, é justificável presumir que esta amostra não representa, do ponto de vista cultural/motivacional, a população portuguesa, sendo necessário pesquisar indivíduos com outro background para traçar mais fielmente a configuração motivacional do País.

Em suma, a pesquisa sugere um nível de motivação para o sucesso superior ao que alguns estudos anteriores sugeriam para a população portuguesa, mas não é possível saber peremptoriamente se tal se deve à especificidade da amostra, a alterações motivacionais que hipoteticamente vêm ocorrendo na população portuguesa, ou mesmo a alterações psicométricas introduzidas no questionário de medida dos motivos. Em qualquer caso, não deixa de merecer especial menção o facto de aqui se reiterar a fraca orientação para o poder e a elevada motivação afiliativa, fazendo justiça ao traço feminino e à “tourada portuguesa" que Hofstede assinalou (1980, 1991, 1997).

Duas notas adicionais, não diretamente tocantes aos três objetivos de pesquisa, são de meritória referência. A primeira aponta para a relação entre a nota média obtida no curso de licenciatura e a remuneração auferida na vida profissional. Embora, genericamente, a relação seja nula (Tabela 2), importa registar o superior nível remuneratório dos indivíduos com maior mérito acadêmico que já colheram mais anos de experiência profissional. Parece, por conseguinte, que esse mérito não se reflete no momento de ingresso no mercado de trabalho, mas após decorridos alguns anos de experiência. Assim ocorrendo, não parece ser a nota, de per si, a explicar a diferença remuneratória, mas sim as motivações e os hábitos de trabalho que presumivelmente interferem no desempenho acadêmico e, posteriormente, no mundo laboral. Veja-se como são semelhantes os padrões empíricos atinentes ao motivo de sucesso e ao mérito acadêmico (Figuras 1.1 e 1.4). Será que a "energia" dos mais motivados para o sucesso se reflete no mérito acadêmico e, decorridos alguns anos de experiência, nas remunerações profissionais?

A segunda nota respeita à relação entre os motivos e o desempenho acadêmico. Quando são controlados os efeitos do curso, correlações significativas emergem: positivas para o sucesso e o poder, mas negativas para a afiliação. A tendência tem sido detectada em estudos anteriores (Rego, 1993, 1995, 1998a; Rego \& Carvalho, 2001, 2002) e tem fundamentos teóricos assim enunciáveis:

a) É natural que os mais motivados para o sucesso, desejosos de ultrapassar padrões de excelência e podendo receber feedback da tarefa (as classificações), do qual são aliás pessoalmente responsáveis, se empenhem mais na vida acadêmica e sejam mais persistentes. O conhecimento de que as elevadas classificações são um passaporte para o Mestrado pode reforçar tais ímpetos; b) É presumível que os mais motivados para o poder encarem as boas classificações como sinais de prestígio e reputação incentivos característicos do motivo. A isso pode acrescer o que foi aduzido para o motivo de sucesso: a constatação de que o mérito acadêmico é uma via de acesso ao mestrado;

c) É plausível que os mais afiliativos, desejosos de estabelecer relações interpessoais quentes e amistosas, propendam mais fortemente para a convivência social em detrimento da aplicação em horas de estudo.

Frise-se, porém, que as correlações são bastante modestas. Esse fato aponta para a necessidade de se estudarem efeitos moderadores, como o grau de dificuldade percebida, que diversas evidências teóricas e empíricas têm sugerido como sendo pertinente para explicar as circunstâncias em que as pessoas se aplicam mais ou menos na execução de uma dada tarefa (McClelland, 1987; McClelland \& Koestner, 1992; McClelland \& Watson, 1973; McKeachie, 1961; Rego, 1998a; Rego \& Carvalho, 2001, 2002; Winter, 1992b).

A última nota que os dados merecem vai para as qualidades psicométricas do questionário de medida dos motivos. Elas revelamse tendencialmente satisfatórias no que concerne: a) ao ajustamento do modelo tri-fatorial aos dados; b) aos coeficientes de consistência interna; c) ao poder preditivo de variáveis-critério. Este dado adicional sugere a possibilidade de estarmos em presença de um instrumento de auto-descrição, cujas potencialidades permitem ombrear com instrumentos projetivos de mais difícil e custosa aplicação. Não pode, todavia, ser obnubilado o fato de as escalas de medida da motivação para o poder denotarem um nível de consistência interna inferior ao desejável (Nunnally, 1978). Esta insuficiência não tem sido apanágio de estudos anteriores realizados em Portugal. Mas uma pesquisa efetuada por Rego e Leite (2003) no Brasil, apontou insuficiências psicométricas como aquelas que aqui se reportam. Embora as magnitudes se situem acima de 0,60, o dado não deixa de merecer atenção metodológica em estudos posteriores.

Em síntese, a evidência empírica assim colhida aponta em três sentidos: 1) contribui para compreender um domínio ainda inexplorado, o da relação entre os motivos e as remunerações; 2) auxilia na compreensão do modo como os motivos podem explicar 
as opções dos indivíduos em matéria de formação acadêmica; 3) fomenta o entendimento do (presumível) padrão motivacional português; 4) faculta indicações adicionais acerca da validade psicométrica de um questionário de medida dos motivos. Pesquisas posteriores são, todavia, necessárias, com amostras de maior dimensão, considerando áreas científicas específicas, recorrendo a metodologias longitudinais que permitam aprimorar o estudo do papel que os motivos exercem nas opções acadêmicas, estudando indivíduos com um mais amplo leque de formações acadêmicas.

\section{Referências}

Atkinson, J. W. (1966a). Motivational determinants of risk-taking behavior. Em J. W. Atkinson \& N. T. Feather (Orgs.), A theory of acbievement motivation (pp. 1129). Huntington, NY: Robert E. Krieger.

Atkinson, J. W. (1966b). Notes concerning the generality of the theory of achievement motivation. Em J. W. Atkinson \& N. T. Feather (Orgs.), A theory of achievement motivation (pp. 163-168). Huntington, NY: Robert E. Krieger.

Atkinson, J. W. (1982). Motivation determinants of thematic apperception. Em A. J. Stewart (Org.), Motivation and society (pp. 3-40). San Francisco, CA: JosseyBass.

Atkinson, J. W. \& Birch, D. (1986). Fundamentals of the dynamics of action. Em J. Kull \& J. W. Atkinson (Orgs.), Motivation, thought, and action (pp. 16-48). New York: Praeger.

Byrne, B. M. (1998). Structural equation modeling with lisrel, prelis, and simplis. London: Lawrence Erlbaum.

Feather, N. T. (1966a). The relationship of persistence at a task to expectation of success and achievement-related motives. Em J. W. Atkinson \& N. T. Feather (Orgs.), A theory of achievement motivation (pp. 117-133). Huntington, NY: Robert E. Krieger.

Feather, N. T. (1966b). Persistence at a difficult task with alternative task of intermediate difficulty. Em J. W. Atkinson \& N. T. Feather (Orgs.), A theory of achievement motivation (pp. 135-146). Huntington, NY: Robert E. Krieger.

Feather, N. T. (1966c). The relationship of expectation of success to $n$ achievement and test anxiety. Em J. W. Atkinson \& N. T. Feather (Orgs.), A theory of achievement motivation (pp. 261-275). Huntington, NY: Robert E. Krieger.

Fleming, J. (1982). Projective and psychometric approaches to measurement: The case of fear of sucess. Em A. J. Stewart (Org.), Motivation and society: A volume in honor of David McClelland (pp. 63-96). San Francisco, CA: Jossey-Bass.

Gannon, M. J. (2001). Understanding global cultures - metaphorical journeys through 23 nations ( $2^{\text {nd }}$ ed.). Thousand Oaks, CA: Sage.

Hernann, M. G. (1980). Assessing the personalities of soviet politburo members. Personality and Social Psychology Bulletin, 6, 332-352.

Heyns, R. W., Veroff, J. \& Atkinson, J. W. (1958). A scoring manual for the affiliation motive. Em J. W. Atkinson (Org.), Motives in fantasy, action and society (pp. 205218). Princeton, NJ: Van Nostrand.

Hofstede, G. (1980). Culture's consequences. Beverly Hills, CA: Sage.

Hofstede, G. (1991). Cultures and organizations: Software of the mind. London: McGraw-Hill.

Hofstede, G. (1997). Entrevista. Executive Digest, Agosto, 40-41.

House, R., Spangler, W. D. \& Woycke, .(1991). Personality and charisma in the US presidency: A psychological theory of leader effectiveness. Administrative Science Quarterly, 36, 364-396.

Jemmott, J. B. (1987). Social motives and susceptibility to disease: Stalking individual differences in health risks. Journal of Personality, 55, 267-298.

Johnson, B. R. (1990). Toward a multidimensional model of entrepreneeurship: The case of achievement motivation and the entrepreneur. Entrepreneurship Theory \& Practice, Spring, 39-54.

Joreskog, K. \& Sorbom, D. (1993). Lisrel 8: Structural equation modeling with the simplis command language. Mahwah, NJ: Scientific Software International.

Koestner, R. \& McClelland, D. C. (1992). The affiliation motive. Em C. P. Smith (Org.), Motivation and personality: Handbook of thematic content analysis (pp. 205210). Cambridge: Cambridge University Press.

Littig, L. W. (1966). Motivational correlates of probability preferences. Em J. W. Atkinson \& N. T. Feather (Orgs.), A theory of achievement motivation (pp. 93102). Huntington, NY: Robert E. Krieger.
Litwin, G. H. (1966). Achievement motivation, expectancy of success, and risk taking behavior. Em J. W. Atkinson \& N. T. Feather (Orgs.), A theory of achievement motivation (pp. 103-115). Huntington, NY: Robert E. Krieger.

Marques, I. (2001). A motivação e a satisfação dos recursos bumanos em projectos temporários. Dissertação de Mestrado em Gestão de Empresas não-publicada, Faculdade de Economia, Universidade Nova de Lisboa. Lisboa, Portugal.

McClelland, D. C. (1962). Business drives and national achievement. Harvard Business Review, Jub-August, 103-105.

McClelland, D. C. (1965). Achievement and entrepreneurship: A longitudinal study. Journal of Personality and Social Psychology, 1, 389-392.

McClelland, D. C. (1972). What is the effect of achievement motivation training in the schools? Teachers College Record, 74, 129-145.

McClelland, D. C. (1976). The achieving society. Princeton, NJ: Van Nostrand. (Original publicado em 1961)

McClelland, D. C. (1982). The need for power, sympathetic activation and illness. Motivation and Emotion, 6, 31-41.

McClelland, D. C. (1987). Human motivation. Cambridge: Cambridge University Press.

McClelland, D. C. (1989). Motivational factors in health and disease. American Psychologist, 44, 675-683.

McClelland, D. C., Atkinson, J. W., Clark, R. A. \& Lowell, E. L. (1953). The Achievement Motive. New York: Appleton-Century-Crofts.

McClelland, D. C. \& Boyatzis, R. E. (1982). The leadership motive pattern and long term success in management. Journal of Applied Psychology, 67, 737-743.

McClelland, D. C. \& Burnham, D. H. (1976). Power is the great motivator. Harvard Business Review, March-April, 100-110.

McClelland, D. C., Davidson, R. J. \& Saron, C. (1985). Stressed power motivation, sympathetic activation, immune function and illness. Advances, 2, 42-52.

McClelland, D. C. \& Koestner, R. (1992). The achievement motive. Em C. P. Smith (Org.), Motivation and personality: Handbook of thematic content analysis (pp. 143152). Cambridge: Cambridge University Press.

McClelland, D. C., Koestner, R. \& Weinberger, J. (1989). How do self-attributed and implicit motives differ? Psychological Revien, 96, 690-702.

McClelland, D. C. \& Pilon, D. A. (1983). Sources of adult motives in patterns of parent behavior in early childhood. Journal of Personality and Social Psychology, 44, 564-574.

McClelland, D. C. \& Teague, G. (1975). Predicting risk preferences among powerrelated tasks. Journal of Personality, 43, 266-285.

McClelland, D.C. \& Watson, R. I. (1973). Power motivation and risk-taking behavior. Journal of Personality, 41, 121-139.

McKeachie, W. J. (1961). Motivation, teaching methods, and college learning. Em M. R. Jones (Org.), Nebraska symposium on motivation. Lincoln: University of Nebraska Press.

Mehrabian, A. (1969). Measures of achieving tendency. Educational and Psychological Measurement, 29, 445-451.

Miller, D. \& Toulouse, J. (1986). Chief executive personality and corporate strategy and structure in small firms. Management Science, 32, 1389-1409.

Murray, H. A. (1938). Explorations in personality. New York: Oxford University Press.

Nunnally, J. C. (1978). Psychometric theory (2 ${ }^{\text {nd }}$ ed.). New York: McGraw-Hill.

Pereira, O. G. (1980). Psicologia económica: Disciplina do futuro. Universidade Nova de Lisboa: Faculdade de Economia.

Raynor, J. O. (1970). Relationships between achievement.related motives, future orientation, and academic performance. Journal of Personality and Social Psychology, 15, 28-33.

Rego, A. (1993). Níveis de motivação e graus de desempenho. Revista Portuguesa de Gestão, II, 69-82.

Rego, A. (1995). O modelo motivacional de McClelland: Uma aplicação. Dissertação de Mestrado não-publicada, Instituto Superior de Ciências do Trabalho e da Empresa. Lisboa, Portugal.

Rego, A. (1998a). Motivações e desempenho de estudantes universitários. Análise Psicológica, 4, 635-646.

Rego, A. (1998b). Configurações motivacionais dos gestores e respectivos impactes nos subordinados. Revista Portuguesa de Gestão, I, 53-65.

Rego, A. (1999). Motivational configurations of managers and their impact on subordinates. Trabalho apresentado no Annual Convention of the International Council of Psychologists, Salem, Massachusetts, USA. 
Rego, A. (2000). Os motivos de sucesso, afiliação e poder- desenvolvimento e validação de um instrumento de medida. Análise Psicológica, 3, 335-344.

Rego, A. \& Carvalho, T. (2001). The achievement, affiliation and power motives: A confirmatory study of the three factor-model. Journal of Applied Psychology, 3, 89-104.

Rego, A. \& Carvalho, T. (2002). Os motivos de sucesso, afiliação e poder: Evidência confirmatória do constructo. Psicologia: Teoria e Pesquisa, 18, 17-26.

Rego, A. \& Jesuíno, J. C. (1999, maio). Motives and conflict management styles. Trabalho apresentado no $2^{\text {th }}$ European Congress on Work and Organizational Psychology, Espoo-Helsinki, Finland.

Rego, A. \& Jesuíno, J. C. (2002). Estilos de gestão do conflito e padrões motivacionais- um estudo exploratório. Comportamento Organizacionale Gestão, 8, 83-97.

Rego, A. \& Leite, E. (2003). Motivos de sucesso, afiliação e poder: Um estudo de validação do constructo no Brasil. Estudos de Psicologia.

Reto, L., Cruz, . \& Lopes, A. (1989/1990). Liderança política-personalidades, conjuntura e representações. Revista de Gestão, ISCTE, VII, 13-17.

Sagie, A. \& Elizur, D. (1999). Achievement motive and entrepreneurial orientation: A structural analysis. Journal of Organizational Behavior, 20, 375-387.

Schmalt, H. \& Sokolowski, K. (2000). Zum gegenwärtigen stand der motivdiagnostik (The current status of motive measurement). Diagnostica, 46, 115-123.

Schmalt, H. (1999). Assessing the achievement motive using the grid technique. Journal of Research in Personality, 33, 109-130.

Schmalt, H. D. (1976). Die messung des leistungsmotivs: The measurement of the acbievement motive. Göttingen, Germany: Hogrefe.

Schmitt, D. P. \& Winter, D. G. (1998). Measuring the motives of soviet leadership and soviet society: Congruence reflected or congruence created? Leadership Quarterly, 9, 293-307.

Schultheiss, O. C. (1999, agosto). Psychological and health correlates of implicit motives. Trabalho apresentado no 107 Annual Convention of the American Psychological Association, Boston, Massachusetts.

Smith, C. P. (1992). Reliability issues. Em C. P. Smith (Org.), Motivation andpersonality: Handbook of thematic content analysis (pp. 126-139). Cambridge: Cambridge University Press.

Sokolowski, K., Schmalt, H., Langens, T. A. \& Puca, R. M. (2000). Assessing achievement, affiliation, and power motives all at once: the multi-motive grid (MMG). Journal of Personality Assessment, 74, 126-145.

Spangler, W. D. (1992). Validity of questionnaire and TAT measures of need for achievement: Two meta-analyses. Psychological Bulletin, 112, 140-154.

Spence, J. T. \& Helmreich, R. L. (1983). Achievement-related motives and behaviors. Em J. T. Spence (Org.), Achievement and achievement motives: Psychological and sociological approaches (pp. 9-74). San Francisco, CA: W. H. Freeman.
Stahl, M. J. \& Harrell, A. M. (1982). Evolution and validation of a behavioral decision theory measurement approach to achievement, power, and affiliation. Journal of Applied Psychology, 67, 744-751.

Steers, R. M. \& Braunstein, D. N. (1976). A behaviorally-based measure of manifest needs in working settings. Journal of Vocational Behavior, 9, 251-266.

Steers, R. M. (1983). Murray's manifest needs theory. Em R. M. Steers \& L. W. Porter (Orgs.), Motivation and work behavior ( $3^{\text {rd }}$ ed.; pp. 42-50). McGraw-Hill.

Veroff, J. (1992a). A scoring manual for the power motive. Em J. W. Atkinson (Org.), Motives in fantasy, action and society (pp. 219-233). Princeton, NJ: Van Nostrand.

Veroff, J. (1992b). Power motivation. Em C. P. Smith (Org.), Motivation andpersonality: Handbook of thematic content analysis (pp. 278-285). Cambridge: Cambridge University Press.

Weinberger, J. \& McClelland, D. C. (1990). Cognitive versus traditional motivational models- irreconcilable or complementary?. Em E. T. Higgins \& R. M. Torrentino (Orgs.), Handbook of motivation and cognition: Fondations of social behavior (Vol. 2; pp. 562-597). New York: The Guilford Press.

Weiner, B. (1989). Human motivation. Hillsdale, NJ: Lawrence Erlbaum.

Winter, D. G. \& Stewart, A. (1977). Content analysis as a technique for assessing political leaders. Em M. G. Hernann (Org.), A psychological examination of political leaders (pp. 27-61). New York: Free Press.

Winter, D. G. (1987). Leader appeal, leader performance, and the motive profiles of leaders and behaviors: A study of american presidents and elections. Journal of Personality and Social Psychology, 52, 196-202.

Winter, D. G. (1991). A motivational model of leadership: Predicting long-term management success from TAT measures of power motivation and responsibility. Leadership Quarterly, 2, 67-80.

Winter, D. G. (1992a). A revised scoring system for the power motive. Em C. P. Smith (Org.), Motivation and personality: Handbook of thematic content analysis (pp. 311-324). Cambridge: Cambridge University Press.

Winter, D. G. (1992b). Power motivation revisited. Em C. P. Smith (Org.), Motivation and personality: Handbook of thematic content analysis (pp. 301-310). Cambridge: Cambridge University Press.

Winter, D. G. (1998). A motivational analysis of the Clinton first term and the 1996 presidencial campaign. Leadership Quarterly, 9, 367-376.

Sobre os autores

Arménio Rego. Universidade de Aveiro.

Aida Isabel Tavares. Departamento de Economia, Gestão e Engenharia Industrial, Universidade de Aveiro.

Miguel Pina e Cunha. Faculdade de Economia, Universidade Nova de Lisboa.

Carlos Cabral Cardoso. Escola de Economia e Gestão, Universidade do Minho

Recebido: 03/06/2003

$1^{a}$ Revisão: $13 / 03 / 2004$

Aceite Final: 14/05/2004 


\section{Anexo A}

\section{Caracterização da amostra}

\begin{tabular}{|c|c|c|}
\hline & & Número de indivíduos \\
\hline \multirow[t]{2}{*}{ Bacharelados } & Estudos superiores de comércio (ESTGA) & 15 \\
\hline & Secretariado de Direcção (ESTGA) & 22 \\
\hline \multirow[t]{5}{*}{ Licenciaturas } & Eng $^{a}$ e gestão industrial (UA) & 50 \\
\hline & Gestão e planeamento em turismo (UA) & 78 \\
\hline & Química industrial e gestão (UA) & 47 \\
\hline & Matemática aplicada à computação (UA) & 34 \\
\hline & Ensino da matemática (UA) & 65 \\
\hline \multirow[t]{13}{*}{ Mestrados } & Gestão das operações (UA ) & 33 \\
\hline & Gestão pública (UA) & 36 \\
\hline & Gestão de recursos humanos (UM) & 18 \\
\hline & MBA (UNL) & 27 \\
\hline & Turismo (UA) & 16 \\
\hline & Comportamento organizacional (ISPA) & 7 \\
\hline & Eng $^{\mathrm{a}}$ Informática (UC) & 23 \\
\hline & Economia (UA) & 20 \\
\hline & Gestão da informação (UA) & 10 \\
\hline & Gestão da ciência, tecnologia e informação (UA) & 7 \\
\hline & Eng $^{\mathrm{a}}$ electrónica e computação (UP) & 12 \\
\hline & Gestão ambiental (UA) & 7 \\
\hline & Outros (incluindo não-respostas) & 72 \\
\hline
\end{tabular}

Nota.ESTGA: Escola Superior de Tecnologia e Gestão de Águeda

UA: Universidade de Aveiro

UM: Universidade do Minho

UNL: Universidade Nova de Lisboa

UC: Universidade de Coimbra

UP: Universidade do Porto

ISPA: Instituto Superior de Psicologia Aplicada 